\title{
Argon Plasma Coagulation in Enhancing the Healing of Solitary Rectal Ulcer Syndrome \& Controlling Its Bleeding
}

\author{
Mohammad Shaikhani, Taha Karbuli, Nasir A. Alqazi, Hiwa Abu Bakir Hussein, \\ Bakhtyar Salim, Kalandar Kasnazan \\ Kurdistan Center for GIT/Hepatology, Asulaimaneyah-Iraqi, Kurdistan, Iraq \\ Email: shaikhanimohammad@googlemail.com
}

Received 26 February 2014; revised 25 March 2014; accepted 24 April 2014

Copyright (C) 2014 by authors and Scientific Research Publishing Inc.

This work is licensed under the Creative Commons Attribution International License (CC BY). http://creativecommons.org/licenses/by/4.0/

\section{(c) (j) Open Access}

\begin{abstract}
Solitary rectal ulcer syndrome (SRUS) is an uncommon disorder of defecation. Its management is usually unsatisfactory and responds best to surgery especially when there is rectal prolapse. There is a new report of the use of Argon plasma coagulation (APC) to enhance healing of these ulcers \& control its bleeding in a study involving 16 patients. We involved a larger number of 18 patients in this case series to examine the role of APC in enhancing healing of SRUS \& control its bleeding.
\end{abstract}

\section{Keywords}

Solitary Rectal Ulcer Syndrome, Argon Plasma Coagulation, Rectal Prolapse

\section{Introduction}

Solitary rectal ulcer syndrome (SRUS) is an uncommon disorder of defecation. Its management is usually unsatisfactory with conventional non-endoscopic methods and frequently surgery is required specially if rectal prolapse is documented by defecating proctography [1]. Endoscopic Argon plasma coagulation (APC) has been found in case reports, the largest from India, including 12 patients, to control bleeding and enhance ulcer healing [2]. Conventional treatment includes improving bowel habits, use of local agents, dietary fiber and biofeedback. Treatment modalities include sucralfate enema, salicylate enema, corticosteroid enema, and injection of corticosteroid around and within the ulcers [3]-[5]. Sucralfate enemas and human fibrin sealant have been effective in small studies. A therapeutic role for botulinum toxin injection in the external anal sphincter for treatment of SRUS associated with constipation and paradoxical contraction of pelvic floor, external anal sphincter muscles in children may exist [6]. 
Objectives: To evaluate the efficacy and safety of APC in controlling bleeding and enhance healing of 16 patients with SRUS.

\section{Case Report}

Designs: A randomized trial with historical control for the management of 18 consecutive patients with SRUS in addition to the usual recommended treatment.

Setting: The colonoscopy unit of Kurditan center for gastroenterology and hepatology-Asulaimaneyah-Iraqi Kurdistan-Iraq.

Main Outcome Measurements: Control of bleeding \& endoscopic healing of SRUS.

Methods: 18 patients with their ages ranging between 18 \& 52 years, with female/male ratio of 14/4, had SRUS discovered during colonoscopy in patients presenting to the colonoscopy unit of Kurdistan center for gastroenterology \& hepatology, Asulaimaneyah-Iraqi Kurdistan-Iraq, during 2 years period of 2008-2009. The diagnoses were based on clinical, colonoscopic \& histologic findings. Five sessions of APC were applied to the ulcers in each patient every 2 weeks \& ulcers were observed for signs of healing \& bleeding control during subsequent colonoscopies.

\section{Results}

The ages of the patients were between 15 - 25 years with female/male ratio of 3/1. APC controlled bleeding in all 16 patients \& resulted in improvement of healing in all of the patients with average $50 \%$ reduction in the ulcers sizes in 10 patients who had large ulcers more than $3 \mathrm{~cm}$ in diameter \& complete healing in 6 patients who had small ulcers less than $1 \mathrm{~cm}$ in diameter as shown in Table 1 . No adverse complications were noted during the APC sessions. These results are comparable with the healing rates achieved with APC in the Indian study \& higher than the healing rates achieved using the conventional non-endoscopic management plans.

\section{Discussion}

The study was done after taking the informed consent of all patients after they had enough information about the diseases $\&$ the treatment options available. Table 1 shows the effects of APC on healing the ulcers \& controlling their bleeding compared with historical controls mentioned in the Indian study (2). Complete healing was achieved in small ulcers less than $1 \mathrm{~cm}$ in diameter but partial healing was achieved in ulcers more than $3 \mathrm{~cm}$ in diameter (Images 1-6). The only previous study done using APC for treatment of SRUS (2) showed complete healing in 8 patients out of 12 while in this study complete healing occurred in 6 out of 16 specially in patients

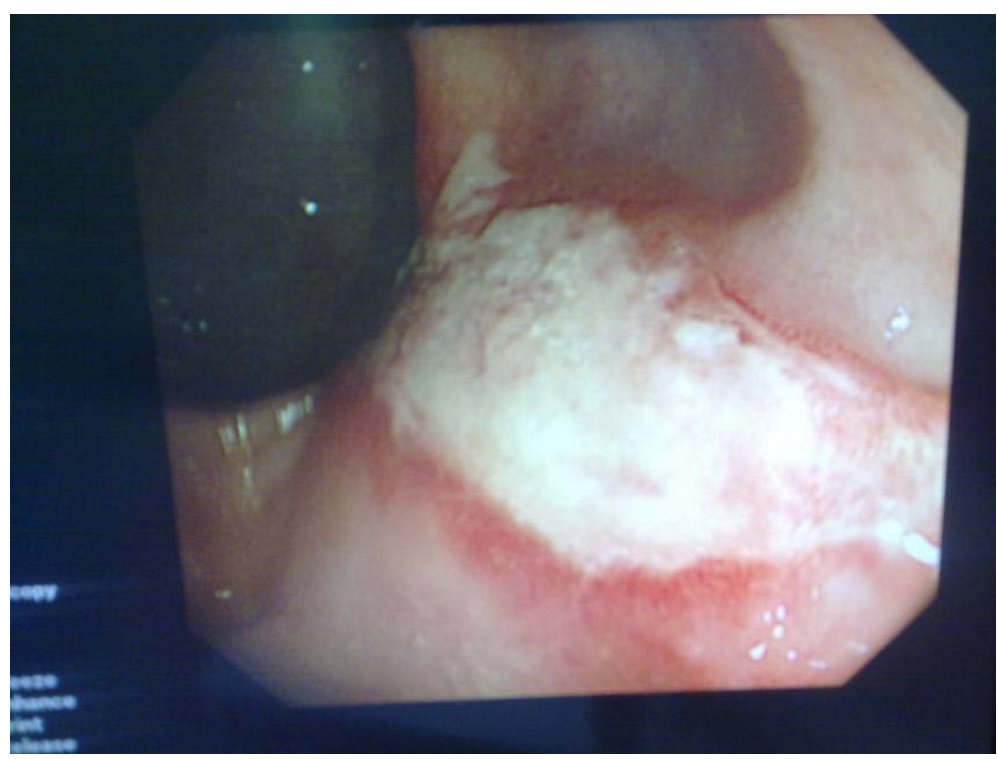

Image 1 . SRUS case 1 , before APC sessions. 
Table 1. Effect of APC in this study compared with treatment effects in historical controls.

\begin{tabular}{cccc}
\hline Outcome measures & Effects of APC in this study & Effects of APC in Reference 2 & $\begin{array}{c}\text { Effect of conventional treatments } \\
\text { in Reference 2 }\end{array}$ \\
\hline Bleeding control & 16 of $16(100 \%)$ & 12 of $12(100 \%)$ & 5 of $12(41.6 \%)$ \\
Partial healing & 10 of $16(62.5 \%)$ & Not mentioned & Not mentioned \\
Complete healing & 6 of $16(37.5 \%)$ & 8 of $12(66.6 \%)$ & 2 of $12(16.6 \%)$ \\
\hline
\end{tabular}

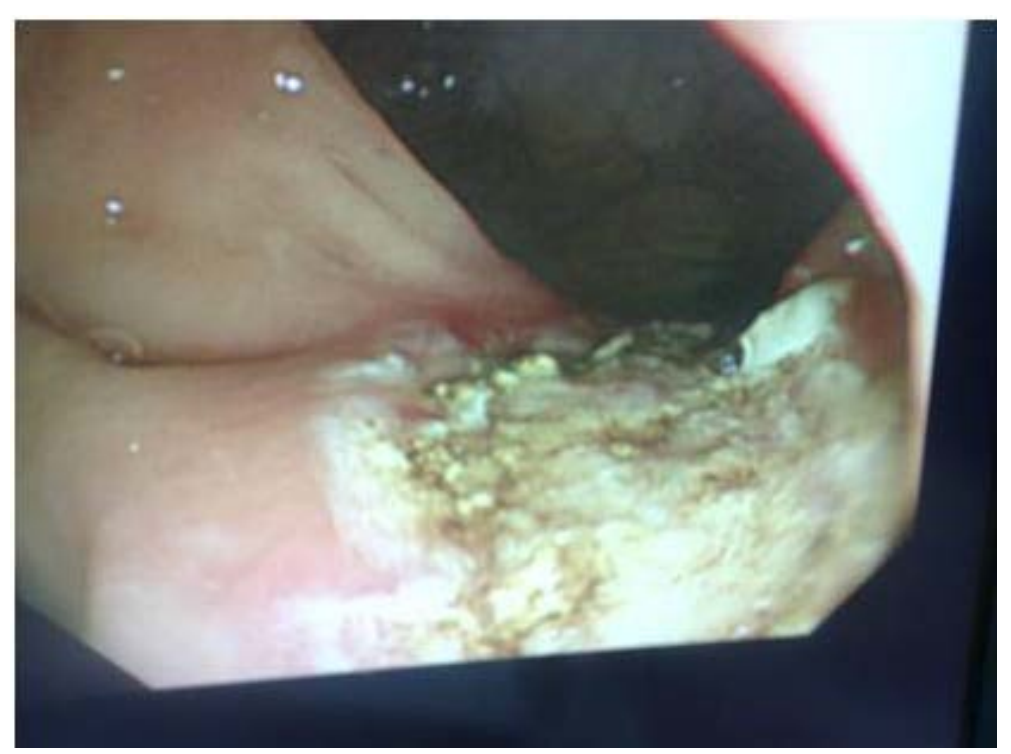

Image 2. SRUS case 1, after APC sessions.

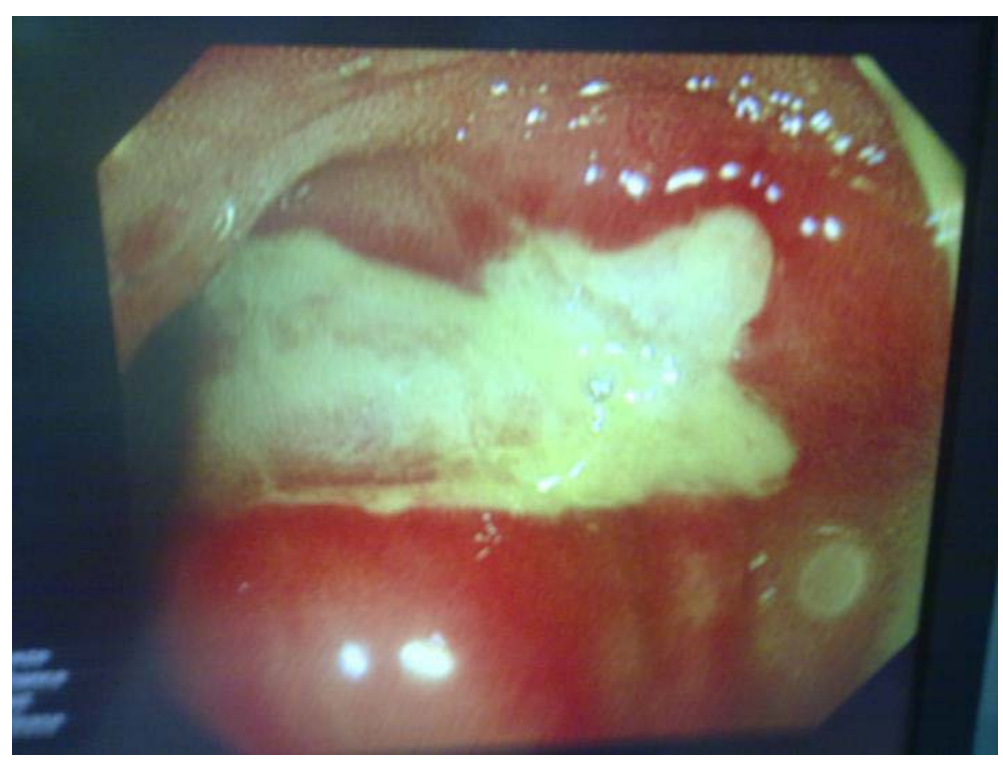

Image 3. SRUS case 2, before APC sessions.

with ulcers of small diameter less than $1 \mathrm{~cm}$, while partial healing occurred in 10 out of 16 specially in ulcers more than $3 \mathrm{~cm}$ in diameter. Control of bleeding was successful in all patients with 16 patients out of the 16 bleeding patients from the ulcers. This result is comparable to the study mentioned above (2). The effects were compared with the effects of conventional non-endoscopic treatment used in managing SRUS patients in the li- 


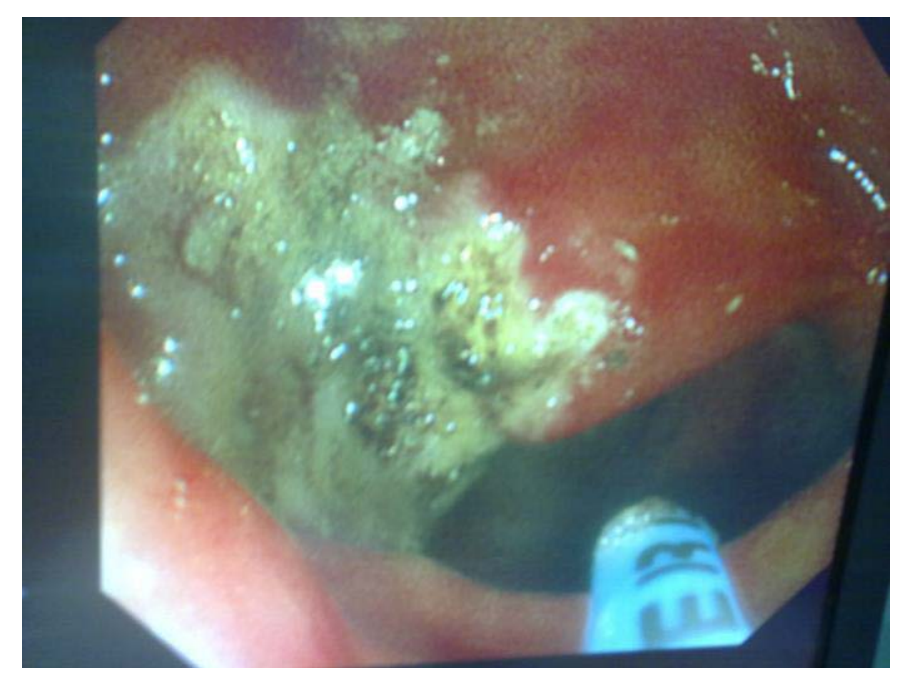

Image 4. SRUS case 2, after APC sessions.

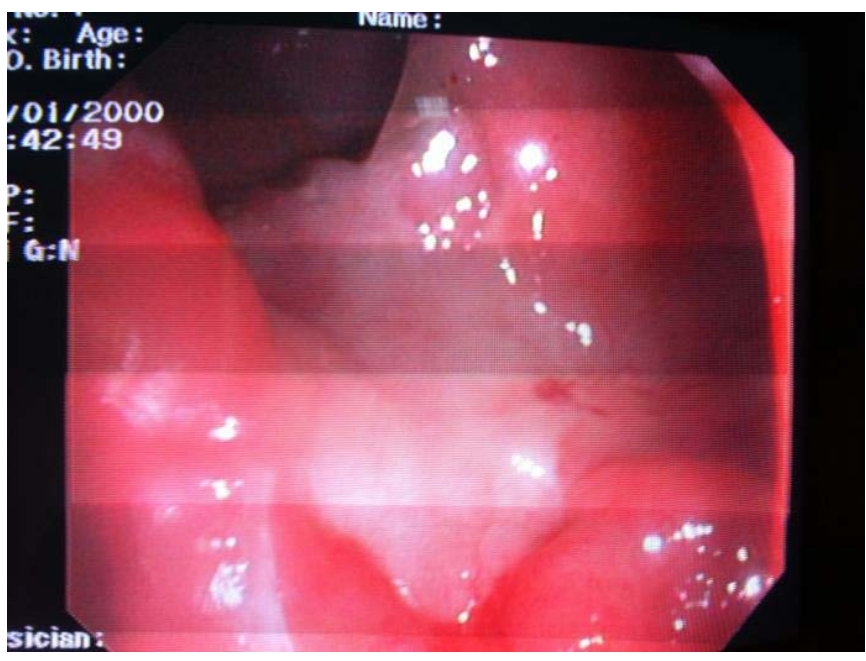

Image 5. SRUS case 3, before APC sessions.

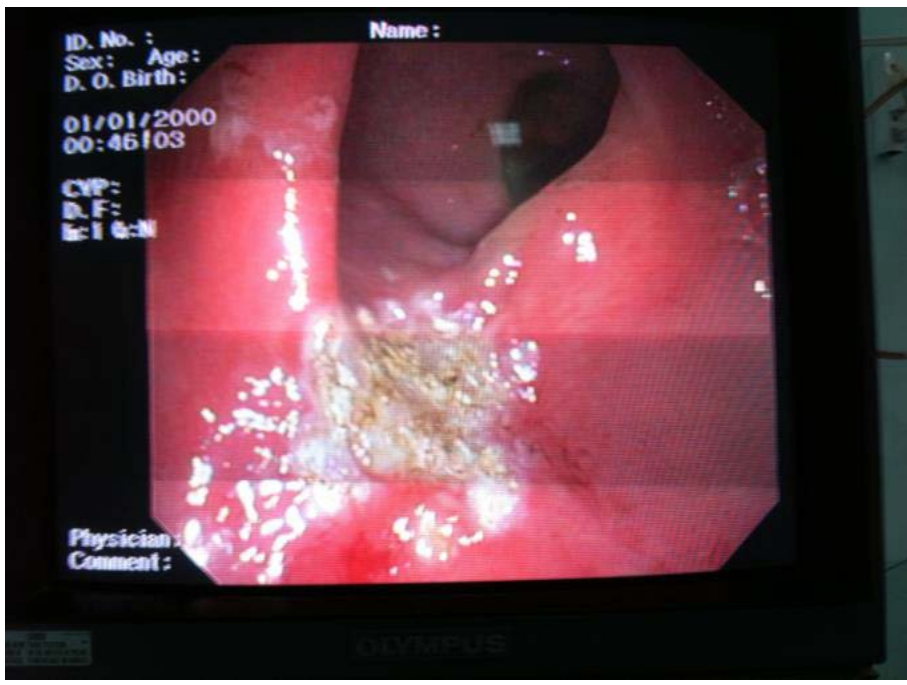

Image 6. SRUS case 3, after APC sessions. 
terature. Two patients had dropped out to follow up so was excluded from the study.

\section{Limitations of the Study}

1) Absence of biofeedback treatment in our center.

2) Defecating barium or MRI proctography was not done for the patients to detect subclinical rectal prolapse, also being not available in our center.

\section{Conclusion}

The largest number of patients with SRUS who underwent APC therapy reported to date. APC sessions resulted in control of bleeding in all SRUS cases; enhanced healing of most patients and completed healing in 8/16 patients. These results are comparable with the healing rates achieved with APC in the Indian study and higher than the healing rates achieved using the conventional non-endoscopic management plans. APC can be an important adjuvant therapy to the conventional non-endoscopic management plans described for this condition.

\section{References}

[1] Bulut, T., Canbay, E., Yamaner, S., Gulluoglu, M. and Bugra, D. (2011) Solitary Rectal Ulcer Syndrome: Exploring Possible Management Options. International Surgery, 96, 45-50. http://dx.doi.org/10.9738/1376.1

[2] Somani, S.K., Ghosh, A., Avasthi, G., Goyal, R. and Gupta, P. (2010) Healing of Solitary Rectal Ulcers with Multiple Sessions of Argon Plasma Coagulation. Digestive Endoscopy, 22, 107-111. http://dx.doi.org/10.1111/j.1443-1661.2010.00941.x

[3] Abid, S., Khawaja, A., Bhimani, S.A., Ahmad, Z., Hamid, S. and Jafri, W. (2012) The Clinical, Endoscopic and Histological Spectrum of the Solitary Rectal Ulcer Syndrome: A Single-Center Experience of 116 Cases. BMC Gastroenterology, 12, 72. http://dx.doi.org/10.1186/1471-230X-12-72

[4] Perito, E.R., Mileti, E., Dalal, D.H., Cho, S.J., Ferrell, L.D., McCracken, M., et al. (2012) Solitary Rectal Ulcer Syndrome in Children and Adolescents. Journal of Pediatric Gastroenterology and Nutrition, 54, 266-270. http://dx.doi.org/10.1097/MPG.0b013e318240bba5

[5] Swatton, A. (2009) Solitary Rectal Ulcer Syndrome: Physiology and Treatment Options. British Journal of Nursing, 18, 1312-1315.

[6] Bulut, T., Canbay, E., Yamaner, S., Gulluoglu, M. and Bugra, D. (2011) Solitary Rectal Ulcer Syndrome: Exploring Possible Management Options. International Surgery, 96, 45-50. http://dx.doi.org/10.9738/1376.1 